\title{
Morphology, histochemistry and glycosylation of the placenta and associated tissues in the European hedgehog (Erinaceus europaeus)
}

Dol:

10.1016/j.placenta.2016.09.010

\section{Document Version}

Accepted author manuscript

Link to publication record in Manchester Research Explorer

\section{Citation for published version (APA):}

Jones, C. J. P., Carter, A. M., Allen, W. R., \& Wilsher, S. A. (2016). Morphology, histochemistry and glycosylation of the placenta and associated tissues in the European hedgehog (Erinaceus europaeus). Placenta, 48, 1-12. https://doi.org/10.1016/j.placenta.2016.09.010

\section{Published in:}

Placenta

\section{Citing this paper}

Please note that where the full-text provided on Manchester Research Explorer is the Author Accepted Manuscript or Proof version this may differ from the final Published version. If citing, it is advised that you check and use the publisher's definitive version.

\section{General rights}

Copyright and moral rights for the publications made accessible in the Research Explorer are retained by the authors and/or other copyright owners and it is a condition of accessing publications that users recognise and abide by the legal requirements associated with these rights.

\section{Takedown policy}

If you believe that this document breaches copyright please refer to the University of Manchester's Takedown Procedures [http://man.ac.uk/04Y6Bo] or contact uml.scholarlycommunications@manchester.ac.uk providing relevant details, so we can investigate your claim.

\section{OPEN ACCESS}


Morphology, histochemistry and glycosylation of the placenta and associated tissues in the European hedgehog (Erinaceus europaeus)

Carolyn J. P. Jones ${ }^{a^{*}}$, A. M. Carter ${ }^{b}$, W. R. Allen ${ }^{c}$ and Sandra A. Wilsher ${ }^{c}$

${ }^{a}$ Maternal and Fetal Health Research Centre, Division of Developmental Biology and Medicine, School of Medical Sciences, Faculty of Biology, Medicine and Health, University of Manchester, St Mary's Hospital, Oxford Road, Manchester M13 9WL, U.K.

${ }^{b}$ Cardiovascular and Renal Research, Institute of Molecular Medicine, University of Southern Denmark, Odense, Denmark.

"The Paul Mellon Laboratory, "Brunswick", 18 Woodditton Road, Newmarket, Suffolk CB8 9BJ, U.K.

*Author for correspondence: Dr Carolyn Jones, Maternal and Fetal Health Research Centre, Division of Developmental Biology and Medicine, School of Medical Sciences, Faculty of Biology, Medicine and Health, University of Manchester, St Mary's Hospital 5th floor (Research), Oxford Road, Manchester M13 9WL

Tel: 44(0)161 7016953

Fax: 44(0)161 7016971

Email: carolyn.jones@manchester.ac.uk 


\section{Abstract}

Introduction. There are few descriptions of the placenta and associated tissues of the European hedgehog (Erinaceus europaeus) and here we present findings on a near-term pregnant specimen.

Methods. Tissues were examined grossly and then formalin fixed and wax-embedded for histology and immunocytochemistry (cytokeratin) and resin embedded for lectin histochemistry.

Results: Each of four well-developed and near term hoglets displayed a discoid, haemochorial placenta with typical labyrinth and spongy zones. In addition there was a paraplacenta incorporating Reichert's membrane and a largely detached yolk sac. The trophoblast of the placenta contained diverse populations of granule which expressed most classes of glycan. Intercellular membranes were also glycosylated and this tended to be heavier in the labyrinth zone. Fetal capillary endothelium had glycosylated apical surfaces expressing sialic acid and various other glycans. Glycogen was present in large cells situated between the spongy zone and the endometrium. Trophoblast cells in the placental disc and under Reichert's membrane, as well as yolk sac endoderm and mesothelium, were cytokeratin positive. Reichert's membrane was heavily glycosylated. Yolk sac inner and outer endoderm expressed similar glycans except for $\mathrm{N}$ acetylgalactosamine residues in endodermal acini.

Discussion. New features of near-term hedgehog placenta and associated tissues are presented, including their glycosylation, and novel yolk sac acinar structures are described. The trophoblast of the placental disc showed significant differences from that underlying Reichert's membrane while the glycan composition of the membrane itself showed some similarity to that of rat thereby implying a degree of biochemical conservation of this structure.

Key words: Placenta; Reichert's membrane; yolk sac; histology; lectins; cytokeratin 


\section{Highlights}

- The near-term placenta of Erinaceus europaeus was discoid and haemochorial

- It was composed of labyrinth, spongy and junctional zones with a paraplacenta

- Yolk sac haematopoiesis was still found to be present.

- The yolk sac contained endodermal acini with a specific surface glycan composition

- Trophoblast under Reichert's membrane was glycogen rich unlike that found elsewhere 
The West European hedgehog (Erinaceus europaeus) has iconic status among embryologists as it was one of the first species subjected to a detailed study of placentation [1]. Only two subsequent descriptions of the fetal membranes have been published $[2,3]$. Some information is available on the African hedgehogs, Atelerix frontalis [4,5] and A. albiventris [6] and the gymnure (Echinosorex gymnura) [7], which are also members of the Erinaceidae family.

7 In the present study, the placentae of a late-pregnant hedgehog were examined grossly, histologically, immunohistochemically and by lectin histochemistry to determine their structure

9 and cellular architecture and to define the types of glycans expressed by the component maternal and fetal tissues. Such investigations are important as lectin histochemistry, applied to semi-thin sections, gives high resolution information on the cellular glycome, providing a useful tool in detecting subtle changes in the biochemistry and function of cells that are not evident using routine histological stains. Here it has been used to identify alterations in cell glycosylation that relate to the positions of cells within the placental disc and yolk sac, reflecting local differences in function and secretory ability.

\section{Material and Methods}

\subsection{Animal}

Examination of a recent road-kill hedgehog revealed a gravid uterus with 4 large pregnancy bulges, each containing a well-developed, near-term hoglet with crown-rump lengths that ranged from about $5.5-6.0 \mathrm{~cm}$ (Figure 1A). The short umbilical cords were severed to expose the flattened 
discoid placentae. Wedges (1-2 cm wide) were cut from the outer edge towards the centre of each placental disc and fixed in $10 \%$ neutral buffered formalin for 4 days.

\subsection{Histology and immunocytochemistry}

Pieces of fixed tissue were trimmed and embedded in paraffin wax for sectioning at $5 \mu \mathrm{m}$ prior to staining for conventional histology with haematoxylin and eosin (H \& E) or Giemsa (for the yolk sac). Other sections for immunocytochemistry were dewaxed at $56^{\circ} \mathrm{C}$ overnight, immersed in a high pH antigen masking solution (Dako PT link; Dako UK Limited, Ely, Cambs, UK) and heated to $97^{\circ} \mathrm{C}$ for $20 \mathrm{~min}$. After cooling, the slides were rinsed in PBS and transferred to a Dako Plus Autostainer (Dako UK) where a mouse monoclonal antibody generated against pancytokeratin (MNF-116, Dako UK at 1:200 dilution) and appropriate secondary antibody (Dako EnVision HRP labelled polymer anti rabbit and mouse antibody) were each applied for 30 mins. The secondary antibody, blocking reagents, buffers, substrate, chromagen and nuclear stain were all EnVision FLEX reagents (Dako UK) optimised for use in the Autostainer Plus. After staining, slides were dehydrated, cleared and mounted in DPX. A negative control was run by replacing the primary antibody with an unrelated monoclonal antibody.

\subsection{Lectin histochemistry}

Strips of formalin-fixed placenta were embedded in epoxy resin (TAAB Laboratories Equipment Ltd., Aldermaston, UK) prior to cutting $0.75 \mu \mathrm{m}$ sections with a $3 \mathrm{~mm}$ diamond knife and mounting them on multispot slides (C.A. Hendley, Essex, UK) Ltd, composed of four wells each $12 \mathrm{~mm}$ in diameter. These were dried for 2 days at $50^{\circ} \mathrm{C}$ and stained with a panel of 25 lectins and an avidinbiotin revealing system as previously described [8] except that SNA-1 was used at a concentration of $50 \mu \mathrm{g} / \mathrm{ml}$. Major binding specificities of the lectins are shown in Table 1. Sections stained with 
AHA, ECA, SBA, SNA-1, MAA, PAA and WGA were treated with 0.1 units $/ \mathrm{ml}$ neuraminidase $(0.1$ units/ml, type VI from Clostridium perfringens, Sigma) for $2 \mathrm{~h}$ at $37^{\circ} \mathrm{C}$ to cleave off terminal sialic acid before incubation in the lectin. Controls were carried out as previously described [8] and as a control for glycogen, sections were pre-digested with $1 \%$ amylase (Sigma) in distilled water at $37^{\circ} \mathrm{C}$ for $30 \mathrm{~min}$, then washed under running water before incubation in BSA-II. Sections were examined under an Olympus BX41 microscope (Tokyo, Japan) where staining intensity was assessed over 3 sections each of two full-depth blocks of tissue (placenta and adjoining paraplacenta) and 3 sections from one block of yolk sac and allocated a grade from 0 (negative) to 4 (intense staining) and granule density from +/- (sparse) to ++++ (closely packed). Where there was variation in staining intensity, the range is denoted in the tables.

\section{Results}

\subsection{Histology of placental disc and placental bed}

The placental disc comprised 3 principal zones: a labyrinth and spongy zone, both cytokeratin positive (Fig. 1B, 2A) and a mixed population of cells at the fetal-maternal interface (Figs. 1F, G). The fetal-facing surface (chorionic plate) contained connective tissue and small to medium size branches of umbilical arteries and veins and overlay medium size maternal blood channels lined by trophoblast (Fig. 1C). In all vessels, the fetal and maternal erythrocytes could be distinguished by the larger size of the former (Fig 1D). Although connections between fetal capillaries could be seen entering into veins, we did not encounter arteries descending through the labyrinth to supply the capillaries. Occasional nucleated erythrocytes were present. 
64 In the labyrinth, fetal capillaries ran parallel to trophoblast-lined maternal blood channels (Fig. 1D). The spongy zone, comprising trophoblast with maternal blood spaces (Fig. 1E), was less extensive in this near term specimen than that described for earlier stages by Hubrecht [1] and Morris $[2,3]$. Trophoblast cells here were often binucleate. At the fetal-maternal interface existed a mixed population of cells, most of which were small with a high nuclear-to-cytoplasm ratio and darkly staining nuclei, containing little or no cytokeratin. Interspersed with these were larger cells that stained strongly for cytokeratin and often contained granules or vacuoles (Fig. 1F,G). They occasionally formed clusters and may correspond to the trophoblast giant cells (TGCS) mentioned by Carter and Enders [5], or the deciduofracts described by Hubrecht [1].

A thick layer of decidualised endometrium existed beneath the placental disc followed by the myometrium. Many sections of maternal vessels were found in the placental bed. Sometimes they were surrounded by cytokeratin-positive cells, presumed to be trophoblast, but these cells were never found in the lumen, as they are in the gymnure [7], and only rarely in the tunica media.

Large maternal blood channels ran from the maternal side of the placental disc to the fetal surface where they branched at right angles (Fig 2A); they supplied the smaller, trophoblast-lined channels that ran from the fetal to the maternal side. Fetal capillaries ran parallel to them probably in the opposite direction, allowing for countercurrent exchange, as suggested for the gymnure by Meister and Davis [7].

\subsection{Lectin histochemistry of placenta}

The results of lectin staining are summarized in Table 1. 
The trophoblast of the labyrinth zone contained many uniformly-sized, clear vacuoles which may have been extracted fat droplets (Fig. 3A), as well as some darkly stained granules particularly evident with GNA (Fig. 3B) and which also stained up with the majority of lectins (see table 1). Other granules were often more threadlike and they selectively bound VVA and HPA. Surface membranes strongly bound CON A, PSA (Fig. 3A), ePHA, ALA, DSA, STA, WGA and SNA-1. AHA bound variably to granules, both before and after neuraminidase pre-treatment, whereas ECA and SBA stained only after removal of terminal sialic acids (Figs. $3 C$ and D). MPA, LEA and MAA bound moderately-to-strongly (Figs 3E, F) but LTA less so. Only weak membrane staining was found with I-PHA (Fig. 3G) and HPA and both these glycans were even more weakly expressed in the cytoplasm.

Fetal capillaries were difficult to distinguish and the staining of their endothelial surfaces was often hard to separate from erythrocyte glycan expression. The endothelial cell surface was generally more glycosylated than the cytosol and bound CON A, PSA, e-PHA, MPA, (Fig. 3E), DSA, STA, WGA and MAA (Fig. 3F). Both AHA and ECA stained more intensely after neuraminidase (Figs $3 \mathrm{C}$ and $\mathrm{D})$; the basal surface appeared more reactive with $\mathrm{ECA}$, possibly reflecting the presence of basal laminae. With I-PHA (Fig. 3G), HPA, ECA and WFA, faint stippling of endothelial cell cytoplasm was sometimes evident..

In the spongy zone, both the apical and lateral surfaces of the often-binucleate trophoblast cells, (Figs $3 \mathrm{H}, \mathrm{I}, \mathrm{L}$ ), were heavily glycosylated as in the labyrinth, although LEA and AHA stained less prominently. The intracellular granules were more easily identifiable and these were highlighted particularly well with GNA, PSA (Fig. 3H), ePHA, ALA (Fig. 3I), DSA, LEA and HPA. A certain degree of intracellular heterogeneity was evident, especially with AHA (Fig. 3J). Thread-like or granular 
inclusions that bound VVA (Fig. 3K) and HPA were again visible. These cells were rich in sialic acid, reflected by a diminution in their binding of WGA after neuraminidase pre-treatment (Figs $3 L, M$ ).

The mixed cell population at the junction between the spongy zone and the endometrium bound almost all the lectins used in the study. Amylase-sensitive glycogen, shown by BSA-Il staining (Fig. $3 \mathrm{~N}, \mathrm{O})$, was present in some of the giant cells and in the smooth muscle cells around large blood vessels, though absent in both the spongy zone and labyrinth trophoblast.

In all areas, neuraminidase pre-treatment resulted in a loss of staining of MAA and WGA with little change in SNA-1 staining. PAA remained negative while AHA, ECA and SBA staining generally increased as described above. Amylase pre-treatment resulted in a loss of staining by BSA-II and other controls resulted in an absence, or reduction, of staining as described previously [8].

\subsection{Paraplacenta}

Lateral to the disc (Fig. 1B) was a paraplacental structure comprising three elements (Fig. 4).

Innermost and facing the exocoelom was a single layer of mesothelium, continuous with a layer of cells covering the placental disc. Beneath this occurred Reichert's membrane, a homogeneous layer some $20-30 \mu m$ thick. At the opposite side and facing the uterine epithelium were cytokeratin-positive trophoblast cells (Fig. 4A). This layer of large cells, some of which were binucleate or possibly multinucleate, especially near the junction with the placental disc, was 5-6 cells deep and it rested on a substratum of extracellular matrix interspersed with granules and cells. Large nuclei could be discerned within the trophoblast cells, but there were also smaller structures that were either nuclei or large vacuoles containing granules.

\subsection{Lectin staining of the paraplacenta}


Reichert's membrane was a fibrous and heavily glycosylated structure with strong binding to CONA, PSA, e-PHA, LTA, ALA, STA and SNA-1 (Fig. 4B-D). There was little or no staining with GNA, I-PHA, UEA-1, BSA-1B4, DBA, VVA and BSA-II and weak to moderate binding with the remaining lectins. After neuraminidase pre-treatment, staining with AHA and ECA increased while SBA and WGA staining remained unchanged; PAA showed a marginal increase in binding. A distinctly fibrillar substructure was seen running longitudinally through some areas of the membrane (Figs 4B, D and E), which probably reflected orientation of fibrils. The overlying mesothelial cells bound many lectins intensely (CONA, PSA, e-PHA, ALA, MPA, WFA, DSA, STA, WGA, SNA-1, MAA, Fig 4). Only UEA-1, DBA, AHA, BSA-1B 4 and -II (Fig. 4F, H, I) were unreactive and other lectins showed weak staining. In some cases, suggestions of secretion by these cells could be seen on the upper aspect of the membrane e.g. with WFA, DSA and AHA after neuraminidase (Figs 4E and G). Under Reichert's membrane, the trophoblast cells showed heavily glycosylated cell membranes, often similar to the mesothelium though with less PSA, ECA, MPA and HPA binding and more by PAA after neuraminidase (Fig. 4J). Occasional membranes stained up more strongly than others (e.g. with AHA, Fig 4G) and these may reflect the presence of vessels. BSA-1B 4 (Fig. 4H), LEA, SBA, WFA and PAA bound strongly to the trophoblast cell membranes here while remaining negative in the placental disc. Likewise, BSA-II bound to copious amounts of intracellular amylase-sensitive glycogen (Fig. 4I), compared to only isolated foci in the placental junctional zone (Fig. 3N). Lectin staining showed clearly the nuclear/vacuolar structures and membranous infoldings in the giant cells abutting the Reichert's membrane near the placental disc (Fig. 4J). 
By late gestation, the yolk sac has been dislodged from the uterine wall, although its vasculature is still supplied by the vitelline vessels (Figure $1 \mathrm{~A}$ ). Thus it is suspended in the exocoelom and lined on that side by mesothelium. At the opposite surface, facing the yolk sac cavity, were columnar endodermal cells (Fig 2B). In places, this layer extended down to form structures resembling acini lined by endoderm (Fig. 2C), which often contained secretory material. Both these epithelia were cytokeratin-positive (Fig. 5A) though less so for the inner endodermal cells, and all bore microvilli that were especially prominent in the acini. The area between them contained connective tissue with vitelline blood vessels and numerous haematopoietic islets (Figs 2B-F). The latter contained nucleated erythrocytes at various stages of maturity (Fig. 2D), and Giemsa staining identified the presence of cells with eosinophilic and small basophilic granules of indeterminate maturity (Figs. $2 E, F)$.

The mesothelial surface of the yolk sac was heavily glycosylated (see Table 2) and it bound CON A (Fig. 5B), PSA, e-PHA, ALA, MPA, GNA, DSA, STA, LEA, SNA-1, MAA, PAA and WGA. There was also patchy staining with WFA, ECA and PAA and neuraminidase increased the level of staining with AHA, ECA, SBA and PAA (Fig. 5C-F). There was little reduction in the heavy staining with SNA-1 after neuraminidase pre-treatment, or of MAA in this particular cell layer (Fig. 5G, H). There was little or no staining with the other lectins. The endodermal cell surface showed a similar pattern of staining apart from little binding of GNA (Fig. 5I), no staining with LEA or WFA and stronger ECA staining before neuraminidase pre-treatment; PAA did not bind here at all. SBA after neuraminidase (Fig. 5F) and STA showed slightly weaker staining of this layer than of the mesothelium. Many diffuse endodermal granules were seen when staining with CON A, ALA, MPA, 
and AHA and ECA after neuraminidase (Figs 5B,D); more distinct, darkly staining granules were observed with PSA, e-PHA, GNA (Fig. 5I), DSA, STA, MAA, SNA-1, (Figs 5G, K) and WGA, with and without neuraminidase. The inner endoderm cells and those forming the acini showed a similar staining pattern to the outer cells, but often with stronger staining of the microvillous apical surfaces; these also bound SBA after neuraminidase, HPA and VVA, the latter selectively (Fig. $5 \mathrm{~J}$ ).

Occasional darkly staining granules (arrows) could be seen in the sub-apical cytoplasm with VVA as well as intensely stained secretions in the acinar lumen, also evident with other lectins such as CON A, MAA, SNA-1 and MPA (Figs 5 B, G, K and N). Inner endodermal cells, and some outer ones, bound BSA-II (Fig. 5L); HPA bound in a similar pattern though more weakly (Fig. 5M). Fine granules, seen in sections without obvious stain (e.g. 5C, E), were also present in the negative controls. Endothelial cells were difficult to detect; they bound CON A, PSA, e-PHA, ALA, MPA (Fig. 5N), DSA, STA, SNA-1, MAA and WGA and also AHA and ECA after neuraminidase treatments.

\section{Discussion}

The classic paper by Hubrecht [1] gave detailed descriptions and hand-drawn illustrations of almost all stages of placental development in Erinaceus europaeus. Morris [2, 3] extended these findings by measuring nitrogen levels in the yolk sac during pregnancy, and identifying RNA, glycogen, lipoidal material, reticulin, elastic tissue, mucopolysaccharides, ferric iron and alkaline phosphatase in various tissues. However, his use of the Periodic-Acid-Schiff reagent gave little information about the types of glycan present, which we have now resolved using lectin histochemistry.

Both the spongy zone and the labyrinth in the placental disc of the hedgehog are composed of trophoblast cells with heavily glycosylated plasma membranes. The presence of clear vacuoles in 

these cells no doubt corresponds to the lipoidal material described by Morris [3]. Generally, the pattern of lectin binding is similar in these two areas although $\mathrm{N}$-acetyl glucosamine oligomers (LEA) and $\alpha 2,3$-linked sialic acid residues (MAA) are more evident in the labyrinth. Most classes of glycans are expressed, in particular complex $\mathrm{N}$-linked glycans (CONA, PSA, e-PHA), $\alpha 1,6$-linked fucosyl residues (ALA), terminal and subterminal $\beta$-galactose (AHA with and without neuraminidase), subterminal $\mathrm{N}$-acetyl lactosamine (ECA after neuraminidase) and $\mathrm{N}$-acetyl glucosamine oligomers (DSA, STA, LEA, WGA). N-acetyl galactosamine termini (VVA, HPA) are not common on cell surfaces although they are present in granular or threadlike particles in the spongy trophoblast which, from their profiles, may have been Golgi saccules, while subterminal residues (SBA after neuraminidase) are evident in both areas. In both layers, $\alpha 2,6$-linked (SNA-1) is more abundant than $\alpha 2,3$-linked (MAA) and 1,2-linked fucosyl residues (LTA, UEA-1) are generally sparse. The apical surface abutting the maternal blood space shows generally greater glycosylation than the lateral membranes, as would be expected to protect the fetal tissue from circulating maternal antigens. A certain amount of cellular heterogeneity is evident in the distribution of some glycans, especially $\beta$-galactosyl residues (AHA). Many intracellular granules are lysosomal, shown by GNA binding which indicates non-reducing terminal $\alpha \mathrm{D}$-mannose residues [9] suggestive of lysosomes [10]. These are most evident in the spongy trophoblast where they express most glycans apart from some 1,2-linked fucosyl residues (UEA-1), terminal N-acetyl galactosamine (DBA, SBA, WFA) and N-acetyl lactosamine/glucosamine oligomers bound by PAA.

The endothelial surface of the blood capillaries expresses all classes of glycan, the strongest being complex N-glycan (CONA, PSA, e-PHA), some N-acetyl galactosamine residues (MPA), subterminal $\beta$-galactose and $\mathrm{N}$-acetyl lactosamine (AHA and ECA after neuraminidase) and $\mathrm{N}$-acetyl glucosamine and lactosamine (DSA, STA, WGA). Terminal sialic acids are strongly expressed, as in 
most species; the high negative charges associated with sialic acid prevent the fetal erythrocytes from adhering to the capillary wall.

The distribution of amylase-sensitive glycogen, as revealed by BSA-II staining [11], is very restricted and was detected only in the mixed cell layer under the placental disc and around large blood vessels in that area, confirming earlier findings by Morris [3].

The biochemistry and morphology of Reichert's membrane has been intensively studied in the rat and mouse. It is composed mainly of filaments of type IV collagen, as in basal laminae, enclosed within a laminin-containing sheath [12], in parallel layers of 3-8nm thick cords with tubular structures between them. In the rat, autoradiography using ${ }^{3} \mathrm{H}$-proline has shown that parietal endodermal cells secrete proline which is incorporated into the type IV collagen of Reichert's membrane [13-16]. These findings conflict with those of Duval [17] and Amoroso [18] who both claimed that trophoblast secretes Reichert's membrane, as did Salamat et al. [19] who found that carbohydrates are synthesised in trophoblast cells but not in parietal endoderm cells. Jollie [20], however, suggested that both cell layers secrete the membrane, parts of which then fused together. In the present study, the membrane was near term so it was not easy to surmise which cell layer secreted the main components; MAA and WGA binding suggested that the mesothelium has a more intensely stained basal plasma membrane, although it would be necessary to examine membranes from earlier in gestation to be sure. Morris [2] observed that Reichert's membrane increased in thickness from $5 \mu \mathrm{m}$ in early stages to $25-30 \mu \mathrm{m}$ at term. Our findings confirm previous biochemical analyses of rat Reichert's membrane which showed galactose, mannose, fucose and sialic acid to be present and higher levels of glucosamine than galactosamine [21]. 

and WGA as shown here, and also with Ricinus communis I agglutinin which binds to terminal $\beta$ galactose. AHA has a similar, but not identical, binding site which was not heavily expressed in Erinaceus, implying a high degree of conservation in the membrane with respect to mannosyl, fucosyl and $\mathrm{N}$-acetyl glucosamine residues, but capping of some $\beta$-galactosyl residues in Erinaceus.

The presence of high levels of amylase-sensitive glycogen deposits in the underlying trophoblast cells implies some degree of undifferentiation. In human placenta, glycogen is found in cytotrophoblast cells, especially in early pregnancy [22], and is considered to be an energy source for rapidly dividing cells. It is surprising, therefore, to find large amounts in near-term hedgehog sub-membranous trophoblast which would no longer have to divide to any great extent to accommodate the growing fetus. It was not detectable in the placental disc and the cut off of glycogen deposition was quite abrupt at the junction of the membrane to the disc itself. The role of the occasional giant cells found near the insertion of Reichert's membrane into the main body of the placenta is not clear. The numerous membranous invaginations from the cell surface suggest either fusion of several mononuclear cells or the presence of narrow channels leading to the surface of the membrane, possibly for the purposes of secretion.

254 phosphatase in the yolk sac of Erinaceus, apart from the localisation of some PAS-positive material activity associated with yolk-sac function; both surfaces are covered with microvilli which are nothing has been reported about glycan distribution. Both surfaces of the hedgehog yolk sac were shown to be heavily glycosylated with both $\mathrm{N}$ - and O-linked glycans which reflects the metabolic generally associated with absorptive and enzymatic functions. The yolk sac is involved not only in 
embryonic nutrition but also in biosynthesis and haematopoiesis [23-25] and, in other species, the yolk sac synthesises a wide range of substances, including albumin, alpha-fetoprotein $[26,27]$ and transferrin $[28,29]$, as well as various proteases, phosphatases and other digestive enzymes $[30,31]$. Morris [2] reported continued entry of protein into the yolk-sac fluid during the later stages of pregnancy in the hedgehog, and fibrinogen, possibly of fetal origin, was also found to be present, entering the yolk-sac cavity from the vitelline vessels of the yolk-sac splanchnopleur.

Secretions were clearly evident in the lumina of the acini, heavily glycosylated, though their exact nature was unknown.

\section{The acini in the yolk sac of Erinceus have not previously been described, although there is a} structure in one of Hubrecht's figures [1] that may be a similar structure, though it is shown as a solid ball of cells. The human yolk sac contains tubules which are also secretory [32] but, unlike that of Erinaceus, the human yolk sac is a transitory structure, functioning only up to nine weeks' gestation [33] after which is degenerates. The yolk sac of Erinaceus can also be seen to undertake erythropoiesis until term, which is another unusual feature.

Both microvillous surfaces of the yolk sac - endodermal (inner and outer) and mesothelial expressed complex N-glycan (CON A, PSA and e-PHA) strongly, although tri/tetra-antennary nonbisected glycan (I-PHA) was absent. Fucose in 1-2 linkage (UEA-1, LTA) was not detected though fucose linked 1,6 was abundant throughout the yolk sac. GalNAc $\alpha 1$ and Gal $\alpha 1,3$ Gal $\beta 1$ residues bound by DBA, SBA and BSA-1B $\mathrm{B}_{4}$ were also absent, though GalNAc bound by MPA was widely expressed and SBA staining increased after neuraminidase treatment, showing that some residues were capped by sialic acid. GalNAca1,6Galß1 (WFA) was only found in patches on the mesothelium. GIcNAc oligomers (DSA, STA) and N-Acetyl lactosamine (DSA, ECA) residues were 
also found widely, some of the latter being capped with sialic acid as staining of ECA was increased, especially in the mesothelium, after neuraminidase pre-treatment; GIcNAc oligomers bound by LEA were restricted to the surface of the mesothelium. The presence of granules in the endoderm, heavily stained with GNA, indicates non-reducing terminal a-D-mannose residues [9] which are primarily markers for lysosomal glycoproteins [10] and this is probably reflects the absorptive function of the endoderm. Terminal sialic acid was also present on Galß1,3GalNAc $\beta 1$ bound by AHA throughout the yolk sac as staining increased after neuraminidase pre-treatment. The strong staining throughout with SNA-1 was barely affected by neuraminidase pre-treatment so may have had a linkage not recognized by the neuraminidase used here; $\alpha 2,3$-linked sialic acid was also present (MAA) which was neuraminidase-sensitive apart from that on the mesothelial surface. In most cases, the inner endoderm cell surfaces expressed similar sugars to the outer cells, though more heavily distributed, apart from short sequences of GaINAc bound by VVA and HPA which were present only on the inner endoderm cell surfaces. Occasional granules binding VVA could also be seen in the inner endoderm, and could have been secretory or the result of absorption; the fact that such material was not present on the surface suggests the former. The endoderm cells bound amylase-sensitive BSA-II which is considered a reliable indicator of intracellular glycogen [11], though its binding specificity also includes oligosaccharide chains carrying terminal $\mathrm{N}$-acetyl glucosamine. As previously noted [22], the same pattern of binding, albeit weaker, is found with HPA, consistent with its broad specificity [34] and its ability to bind to a polyglucose gel matrix [35]. The fine granules seen in many sections, including the negative control, may correspond to mitochondria since similar granules of the same size were shown by Morris [3] to stain positively by Kull's method for mitochondria. 
303 In summary, this chance finding of a recently killed, near-term, pregnant hedgehog has enabled a

304 long- overdue, detailed description of the morphology and glycosylation of the haemochorial, 305 discoid placenta and associated tissues of the European hedgehog, Erinaceus europaeus.

\section{Conflict of interest}

307 The authors report no conflicts of interest. The authors alone are responsible for the content and 308 writing of the paper.

\section{Acknowledgements}

310 We are very grateful for the histological expertise of Mrs Sue Gower and also to Dr Alistair Foote 311 for performing the Giemsa staining on the yolk sac tissues.

\section{$312 \quad$ Funding}

313 This research did not receive any specific grant from funding agencies in the public, commercial, or 314 not-for-profit sectors.

\section{References}

316 [1] Hubrecht AAW. The Placentation of Erinaceus europaeus with remarks on the phylogeny of the 317 placenta. Quart J Microscop Sci 1889;30:283-404.

318 [2] Morris B. The yolk-sacs of Erinaceus europaea and Putorius furo. J Embryol Exp Morphol 319 1953;1:147-60.

320 [3] Morris B. Some histochemical observations on the endometrium and the yolk-sac placenta of 321 Erinaceus europaea. J Embryol Exp Morphol 1957;5:184-200. 

Med Sci 1942;7:47-71.

[5] Carter AM, Enders AC. Placentation in mammals once grouped as insectivores. Int J Dev Biol 2010;54:483-93.

[6] Ferner K, Siniza, S, Zeller U. The placentation of Eulipotyphla - reconstructing a morphotype of the mammalian placenta. J Morphol 2014;275:1122-44.

[7] Meister W, Davis DD. Placentation of a primitive insectivore, Echinosorex gymnura. Fieldiana: Zool 1953;35:11-26.

[8] Jones CJ, Carter AM, Aplin JD, Enders AC. Glycosylation at the fetomaternal interface in hemomonochorial placentae from five widely separated species of mammal: is there evidence for convergent evolution? Cells Tiss Org 2007;185:269-84.

[9] Shibuya N, Goldstein IJ, Van Damme EJ, Peumans WJ. Binding properties of a mannose-specific 334

[11] Hennigar RA, Mayfield RK, Harvey JN, Ge ZH, Sens DA. Lectin detection of renal glycogen in rats with short-term streptozotocin-diabetes. Diabetologia 1987;30:804-11.

339 [12] Inoué S, Leblond CP, Laurie GW. Ultrastructure of Reichert's membrane, a multilayered 340 basement membrane in the parietal wall of the rat yolk sac. J Cell Biol 1983;97:1524-37. 
[13] Clark CC, Tomichek EA, Koszalka TR, Minor RR, Kefalides NA. The embryonic rat parietal yolk sac. The role of the parietal endoderm in the biosynthesis of basement membrane collagen and glycoprotein in vitro. J Biol Chem 1975;250:5259-67.

[14] Pierce GB, Jones A, Orfanakis NG, Nakane PK, Lustig L. Biosynthesis of basement membrane by parietal yolk sac cells. Differentiation 1982;23:60-72.

[15] Fatemi SH. The role of secretory granules in the transport of basement membrane components: radioautographic studies of rat parietal yolk sac employing ${ }^{3} \mathrm{H}$-proline as a precursor of type IV collagen. Connect Tissue Res 1987;16:1-14.

[16] Mazariegos MR, Leblond CP, van der Rest M. Radioautographic tracing of ${ }^{3} \mathrm{H}$-proline in the endodermal cells of the parietal yolk sac as an indicator of the biogenesis of basement membrane components. Am J Anat 1987;179:79-93.

[17] Duval M. Le Placenta des Rongeurs. 1892, Vol 2 Felix Alcan, Paris, p. 1-640.

[18] Amoroso AC. Placentation. In “Marshall's Physiology of Reproduction." Vol.2. Ed: Parkes AS. London, Longmans, 1952; p. 127-311.

[19] Salamat M, Götz W, Horster A, Janotte B, Herken R. Ultrastructural localization of carbohydrates in Reichert's membrane of the mouse. Cell Tissue Res 1993;272:375-81.

[20] Jollie WP. Changes in the fine structure of the parietal yolk sac of the rat placenta with increasing gestational age. Am J Anat 1968;122:513-31. 
359 [21] Clark CC, Minor RR, Koszalka TR, Brent RL, Kefalides NA. The embryonic rat parietal yolk sac. 360 Changes in the morphology and composition of its basement membrane during development. Dev 361 Biol. 1975;46:243-61.

362 [22] Jones CJ, Choudhury RH, Aplin JD. Tracking nutrient transfer at the human maternofetal 363 interface from 4 weeks to term. Placenta 2015;36:372-80.

364 [23] Deren JJ, Padykula HA, Wilson TH. Development of structure and function in the mammalian 365 yolk sac. III. The development of amino-acid transport by rabbit yolk sac. Dev Biol 1966;13:370366384.

367 [24] Tiedemann K, Minuth WW. Synthesis of serum proteins by the posthaematopoietic feline 368 yolk sac. Histochemistry 1980; 67:155-167

369 [25] McGrath KE, Palis J. Hematopoiesis in the yolk sac: more than meets the eye. Exp. Hematol $370 \quad 2005 ; 33: 1021-8$.

371 [26] Gitlin D, Perricelli A. Synthesis of serum albumin, prealbumin, alpha-foetoprotein, alpha-1372 antitrypsin and transferrin by the human yolk sac. Nature 1970;228(5275):995-7.

373 [27] Nahon JL, Venetianer A, Sala-Trepat JM. Specific sets of DNase I-hypersensitive sites are 374 associated with the potential and overt expression of the rat albumin and alpha-fetoprotein genes. 375 Proc Natl Acad Sci USA 1987;84:2135-39.

376 [28] Ekblom P, Thesleff I. Control of kidney differentiation by soluble factors secreted by the 377 embryonic liver and the yolk sac. Dev Biol 1985;110:29-38. 
378 [29] Williams CL, Priscott PK, Oliver IT, Yeoh GC. Albumin and transferrin synthesis in whole rat 379 embryo cultures. J Exp Morphol 1986;92:33-41.

380 [30] Miki A, Kugler P. Comparative enzyme histochemical study on the visceral yolk sac endoderm 381 in the rat in vivo and in vitro. Histochemistry 1984;81:409-15.

382 [31] Gossrau R, Graf R. Comparative hydrolase cytochemistry of the mature guinea-pig and 383 marmoset yolk sac with special reference to proteases. Acta Histochem (Jena) 1986;80:135-47.

384 [32] Nogales FF, Dulcey I. The secondary human yolk sac has an immunophenotype

385 indicative of both hepatic and intestinal differentiation. Int J Dev Biol 2012; 56:755-760.

386 [33] Jones CJP, Jauniaux E. Ultrastructure of the materno-fetal interface in the first trimester of 387 pregnancy. Micron 1995; 26:145-73.

388 [34] Hammerström S, Murphy LA, Goldstein IJ, Etzler ME. Carbohydrate binding specificity of four $389 \mathrm{~N}$-acetyl-D-galactosamine-"specific" lectins: Helix pomatia A hemagglutinin, soybean agglutinin, 390 lima bean lectin and Dolichos biflorus lectin. Biochemistry 1977;16:2750-5.

391 [35] Ishiyama I, Uhlenbruck G. On the nature of the anti-dextran activity of the Helix pomatia "anti 392 A" agglutinin. Z Naturforsch B 1971;266:1198-9. 
Figure 1. Diagram of the placenta and paraplacenta of Erinaceus (not to scale). Note that fetal erythrocytes in the fetal capillaries are larger than the maternal red blood cells being carried in the maternal channels and passing through the placenta in the maternal blood spaces which are 398 lined by trophoblast cells.

Figure 2. General anatomy of the placental disc.

A. Hoglet and placenta. Hoglet crown rump length $5.5 \mathrm{~cm}$. Umbilical arteries (UA) and vein (UV), which show branching before reaching the placenta, can be seen as well as the vitelline vessels (VV) connecting to the yolk sac (YS).

B. Overview of placental structure stained to show cytokeratin. On the right, the paraplacenta with mesothelium (Mes) Reichert's membrane (RMem, unstained) and underlying cytokeratinpositive trophoblast cells (Troph) can be seen. Scale bar: $200 \mu \mathrm{m}$.

C. Chorionic plate showing a fetal artery (FA) and vein (FV) overlying a maternal blood channel 407 (MBC). H \& E. Scale bar: $100 \mu \mathrm{m}$.

D. Labyrinth showing the arrangement of fetal capillaries (FC) running alongside maternal blood spaces (MBS). Erythrocytes in fetal capillaries are larger than those in the maternal blood spaces. H \& E. Scale bar: $50 \mu m$. can be seen. H \& E. Scale bar: $50 \mu \mathrm{m}$. 

cells. Scale bar: $50 \mu \mathrm{m}$. bar: $25 \mu \mathrm{m}$

Figure 3: Placental vessel and yolk sac structure.

A. Montage showing cytokeratin staining of a large maternal blood channel (MBC) emerging in the junctional zone (JZ) and traversing the spongy zone (SZ) and labyrinth (Lab) before branching.

421 Scale bar: $200 \mu \mathrm{m}$.

B. Area of yolk sac showing haematopoietic islets containing nucleated erythrocytes (RBC); endodermal cells face the yolk sac cavity while the mesothelium lines the exocoelom. H \& E. Scale bar: $50 \mu \mathrm{m}$.

C. Part of the yolk sac containing acini lined by endoderm cells; their luminae are marked *. H \& E. Scale bar: $50 \mu \mathrm{m}$

D. Haematopoietic islets of the yolk sac showing nucleated erythrocytes at various stages of development as highlighted by differing nuclear sizes. A polychromatophilic normoblast can be seen (arrow). Giemsa. Scale bar: $25 \mu \mathrm{m}$

E. Cells containing eosinophilic granules (arrow) can be seen in the islets. Giemsa. Scale bar: $25 \mu \mathrm{m}$ 
A. The trophoblast cells $(\mathrm{T})$ of the labyrinth contain many clear vacuoles (arrows). Narrow fetal capillaries (fc) run alongside maternal blood spaces (MBS) many of which are devoid of RBC in this section.

B. Many granules bind GNA intensely (arrow).

C. ECA binds to fetal capillaries, especially to the basal surface. Maternal erythrocytes (Mat RBC), which are smaller than those in the fetal capillaries, can be seen in the lower half of the image.

D. After neuraminidase pretreatment $(+N)$, most cell components bind the lectin ECA. membranes.

G. Glycans binding I-PHA are poorly expressed in trophoblast but small granules that bind the lectin are present in some endothelial cells (arrow).

450 I. The maternal blood proteins bind ALA intensely $\left({ }^{*}\right)$ and all cell components, apart from nuclei, 451 are also bound by this lectin. 
454

455

$\mathbf{L}$ and $\mathbf{M}$. The binding of WGA to most components of the trophoblast cells $(\mathbf{L})$ is reduced after the removal of sialic acid by neuraminidase pre-treatment (M).

N. BSA-II binds to components found in giant cells in the junctional zone which are amylase sensitive.

O. BSA-II also binds to amylase-sensitive components in the smooth muscle cells surrounding a large vessel at the base of the placental disc.

\section{Figure 5: Lectin histochemistry of the late gestation paraplacenta and associated structures.}

Scale bars A-G and J: $25 \mu \mathrm{m}, \mathrm{H}: 100 \mu \mathrm{m}, \mathrm{I}: 50 \mu \mathrm{m}$.

A. Reichert's membrane (RM) is covered by mesothelium (Mes), neither layer appears to contain cytokeratin. Underlying it are layers of trophoblast cells $(\mathrm{T})$ that express the protein strongly.

B. Most components of the membrane show a strong affinity for e-PHA. A fibrillar substructure within the membrane can be discerned (arrows). The matrix supporting the membrane contains stained inclusions.

C. LTA stains the membrane strongly but other components only weakly.

D. SNA-1 binds to all the components of the membrane.

E. All components of the membrane bind DSA strongly and the fibrillar substructure is again evident (arrow). A binucleate trophoblast cell can be seen $\left(^{*}\right)$ in the centre of the image.

F. With AHA, occasional vessel membranes are strongly bound. 
G. After neuraminidase pre-treatment, most structures show increased staining with AHA, especially the basal surface of the mesothelium, which appears to show material penetrating the upper aspect of the membrane (arrow).

H. The cell membranes of the trophoblast layer under Reichert's membrane bind BSA-1B 4 intensely, unlike those of the spongy zone (dashed line delineates the edge of the zone) in the placental disc which are completely negative. Staining ceases abruptly at the point where the membrane joins the placental disc.

I. BSA-II binds to amylase-sensitive components in the trophoblast cells under the membrane.

J. Near the junction of the membrane with the main disc, occasional giant cells can be seen with membranous infoldings around their abutment to the membrane (arrow). This section has been stained with PAA after neuraminidase pre-treatment.

\section{Figure 6: Lectin histochemistry of the late gestation yolk sac. The same area has been captured} in all images except for $\mathbf{A}, \mathbf{J}$ and $\mathbf{N}$. Scale bars $50 \mu \mathrm{m}$ except $\mathrm{J}$ and $\mathrm{N}$ which are $25 \mu \mathrm{m}$.

A. Yolk sac showing cytokeratin expression; outer endodermal cells (End) stain more strongly than the inner cells which form acini. Nucleated RBC are in the blood islets and the mesothelium (Mes) is strongly stained.

B. CON A binds to both surfaces and to the inner endoderm. Endodermal acini with secretions are present (arrow).

C. AHA shows no binding to the yolk sac; some endodermal granules show non-specific staining. 
D. After neuraminidase $(+\mathrm{N})$ pre-treatment and removal of terminal sialic acid, AHA binds strongly to the microvillous surfaces of both endodermal cells and mesothelium.

E. The yolk sac is virtually unstained after incubation in SBA.

F. After neuraminidase pre-treatment $(+N)$, there is patchy staining by SBA of the surface endodermal microvilli although inner cell surfaces and acini stain strongly, as does the mesothelium.

G. MAA binds to $\alpha 2,3-$ linked sialic acid which is widely expressed in all components of the yolk sac. Secretions (arrow) are present in the acini.

H. Neuraminidase pre-treatment $(+N)$ removes all MAA staining, except that of the mesothelial 500 surface. probably reflect the presence of lysosomes.

J. Inner endodermal cell surfaces and acini (*) bind VVA strongly. Occasional sub-apical granules 504 (arrows) can be seen.

K. Almost all components of the yolk sac bind SNA-1, including secretions in the acini $\left({ }^{*}\right)$. cells typical of glycogen deposition.

M. HPA shows a similar, although weaker, binding pattern to BSA-II.

N. Endothelial cells can be seen after staining with MPA (arrows). 
Table 1: Lectin staining of Hedgehog placental disc and major binding specificities of the lectins.

(Staining intensity from 1 (weak) to 4 (intense). Particle density from +/- (sparse) to ++++ (abundant). Ap: apical, Lat: lateral)

\begin{tabular}{|c|c|c|c|c|c|c|c|c|c|c|c|}
\hline \multirow[t]{2}{*}{ Lectin } & \multirow[t]{2}{*}{ Source } & \multirow{2}{*}{ Major Specificity } & \multirow{2}{*}{$\begin{array}{l}\text { Placental } \\
\text { Surface }\end{array}$} & \multicolumn{2}{|c|}{ Labyrinth Trophoblast } & \multirow{2}{*}{$\begin{array}{l}\leftarrow \text { Placental } \\
\text { Ap surface }\end{array}$} & \multirow{2}{*}{$\begin{array}{l}\text { Spongy } \\
\text { Lat surface }\end{array}$} & \multirow{2}{*}{ Zone Trophoblast } & \multirow{2}{*}{$\begin{array}{c}\rightarrow \\
\text { Granules }\end{array}$} & \multicolumn{2}{|c|}{ Blood vessels } \\
\hline & & & & Cytoplasm & Granules & & & & & Surface & Cytoplasm \\
\hline GNA & Galanthus nivalis & \multirow{5}{*}{$\begin{array}{l}\text { Glucose or mannose residues in high } \\
\text { mannose, small, bi- tri- or tetra- } \\
\text { antennary, bisected or non bisected } \\
\text { complex } \mathrm{N} \text { - linked sequences }\end{array}$} & 2 & 2 & $3+++$ & 1 & 1 & 1 & $3-4+++$ & 2 & 1 \\
\hline CONA & Canavalia ensiformis & & 3 & 3 & $4++$ & 3 & 2 & 2 & $4++$ & 3 & 2 \\
\hline PSA & Pisum sativum & & 3 & 2 & $4++$ & 3 & 4 & 2 & $4++$ & 3 & 2 \\
\hline ePHA & $\begin{array}{l}\text { Phaseolus vulgaris - } \\
\text { erythroagglutinin }\end{array}$ & & 3 & $2-3$ & $4+$ & 3 & 3 & 2 & $4++$ & 3 & $1-2$ \\
\hline IPHA & Phaseolus vulgaris - leucoagglutinin & & 1 & 1 & 1 & 1 & 1 & 1 & $3++$ & 1 & $2+$ \\
\hline LTA & Lotus tetragonolobus & \multirow{3}{*}{$\begin{array}{l}\text { L-Fucose terminals linked to galactose } \\
\text { or } \mathrm{N} \text {-acetyl glucosamine }\end{array}$} & 2 & 1 & $2+$ & $1-2$ & 1 & 1 & 1 & $1-2$ & 1 \\
\hline UEA-1 & Ulex europaeus-1 & & 0 & 0 & 0 & 0 & 0 & 0 & 0 & 0 & 0 \\
\hline ALA & Aleuria aurantia & & 3 & 2 & $3+$ & 3 & 3 & 2 & $4+++$ & 2 & 1 \\
\hline MPA & Maclura pomifera & \multirow[t]{2}{*}{ Galactose/ $\alpha \mathrm{N}$-acetyl galactosamine } & $2-3$ & 2 & $3+$ & $2-3$ & $2-3$ & 2 & $3++$ & 4 & 2 \\
\hline BSA-1B $B_{4}$ & 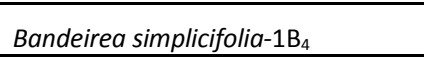 & & 0 & 0 & 0 & 0 & 0 & 0 & 0 & 0 & 0 \\
\hline$\overline{\mathrm{AHA}}$ & Arachis hypogaea & Terminal $\beta$ Galactose & 3 & $2-3$ & $2-3++++$ & 1 & 2 & $1-2$ & $3++++$ & 1 & 1 \\
\hline $\mathrm{AHA}+\mathrm{N}$ & " after neuraminidase & Subterminal $\beta$ Galactose & 3 & 3 & $2-3++++$ & $3-4$ & 3 & 3 & $3++++$ & 3 & 1 \\
\hline ECA & Erythrina cristagalli & Terminal $\mathrm{N}$-acetyllactosamine & 0 & 0 & 0 & 0 & 0 & 0 & 0 & $1-3$ & 1 \\
\hline $\mathrm{ECA}+\mathrm{N}$ & " after neuraminidase & Subterminal $\mathrm{N}$-acetyllactosamine & 4 & 3 & $3-4++$ & 4 & 3 & $2-3$ & $3-4++$ & $2-3$ & 1 \\
\hline DBA & Dolichos biflorus & \multirow[t]{5}{*}{$\alpha \mathrm{N}$-acetylgalactosamine terminals } & 0 & 0 & 0 & 0 & 0 & 0 & 0 & 0 & 0 \\
\hline VVA & Vicia villosa & & 0 & 0 & $3+$ & 0 & 0 & 0 & $3+++$ & 0 & 0 \\
\hline HPA & Helix pomatia & & 1 & 1 & $3+/-$ & 1 & 1 & 1 & $3-4+++$ & $1-2$ & 1 \\
\hline$\overline{\text { WFA }}$ & Wisteria floribunda & & 0 & 0 & 0 & 0 & 0 & 0 & 0 & 1 & $2+$ \\
\hline SBA & Glycine max & & 0 & 0 & 0 & 0 & 0 & 0 & 0 & 0 & 0 \\
\hline $\mathrm{SBA}+\mathrm{N}$ & "after neuraminidase & Subterminal $\alpha \mathrm{N}$-acetylgalactosamine & 2 & $1-2$ & $2-3++++$ & 2 & $1-2$ & $1-2$ & $2-3++++$ & 1 & 1 \\
\hline BSA-II & Bandeirea simplicifolia-II & Terminal $\alpha$ and BNAcetyl glucosamine & 0 & 0 & 0 & 0 & 0 & 0 & 0 & 0 & 0 \\
\hline DSA & Datura stramonium & \multirow{4}{*}{$\begin{array}{l}\mathrm{N} \text {-acetyl-glucosamine oligomers and/ } \\
\text { or } \mathrm{N} \text {-acetyl lactosamine }\end{array}$} & 4 & 2 & $3+$ & 4 & 3 & 2 & $3-4++$ & $2-3$ & 1 \\
\hline STA & Solanum tuberosum & & 4 & $2-3$ & $3-4+$ & 4 & 3 & 2 & $3-4++$ & $2-3$ & 2 \\
\hline LEA & Lycopersicon esculentum & & $2-3$ & $1-2$ & $2-3+++$ & 1 & 1 & 1 & $3-4+++$ & 1 & 1 \\
\hline PAA & Phyttolacca americana & & 0 & 0 & 0 & 0 & 0 & 0 & 0 & 0 & 0 \\
\hline WGA & Triticum vulgaris & $\begin{array}{l}\mathrm{N} \text {-acetyllactosamine, di-N-acetyl } \\
\text { chitobiose, sialic acid }\end{array}$ & 3 & 2 & $3+$ & $2-3$ & $2-3$ & 2 & $3++++$ & $2-3$ & 1 \\
\hline SNA1 & Sambucus nigra & \multirow[t]{2}{*}{ Terminal sialic acid } & 4 & 3 & $4+$ & 4 & 3 & 3 & $4+$ & 3 & 2 \\
\hline MAA & Maackia amurensis & & $2-3$ & $1-2$ & $3+$ & 2 & 2 & $1-2$ & $3+$ & 4 & 2 \\
\hline
\end{tabular}


Table 2: Lectin histochemistry of Reichert's membrane and yolk sac.

(Staining intensity from 1 (weak) to 4 (intense). Particle density from + (sparse) to ++++ (abundant). Surf: surface, Cyt: cytoplasmic; Occ: occasional.)

\section{Reichert's membrane}

\begin{tabular}{|c|c|c|c|c|c|c|c|c|c|c|c|c|c|c|c|c|c|}
\hline \multirow[t]{2}{*}{ Lectin } & \multicolumn{2}{|c|}{ Mesothelium } & \multirow[t]{2}{*}{ Membrane } & \multicolumn{3}{|c|}{ Trophoblast } & \multirow[t]{2}{*}{ Lectin } & \multicolumn{3}{|c|}{ Outer endoderm } & \multicolumn{3}{|c|}{ Inner endoderm } & \multicolumn{2}{|c|}{ Mesothelium } & \multicolumn{2}{|c|}{ Endothelium } \\
\hline & Surf & Cyt & & Surf & Cyt & Granules & & Surf & Cyt & Granules & Surf & Cyt & Granules & Surf & Cyt & Surf & Cyt \\
\hline GNA & $1-3$ & $1-2$ & 1 & 1 & 1 & $4+$ & GNA & 1 & 1 & Occ 4 & 1 & 1 & Occ 4 & $3-4$ & 3 & 1 & 1 \\
\hline CONA & 4 & $2-3$ & 3 & 3 & $1-2$ & $4+++$ & CONA & $3-4$ & 3 & 3 & $3-4$ & 3 & 3 & 4 & 2 & $2-1$ & $1-2$ \\
\hline PSA & 4 & $1-2$ & 3 & $1-2$ & $1-2$ & $4-/+$ & PSA & 4 & 1 & $4+$ & 4 & 1 & $4+$ & 4 & 1 & 3 & 1 \\
\hline ePHA & 4 & $1-2$ & 3 & $3-4$ & 1 & $4++$ & ePHA & 4 & 1 & $4-/+$ & 4 & 1 & $4-/+$ & 4 & $1-2$ & 3 & 3 \\
\hline IPHA & $1-2$ & 1 & 1 & $1-3$ & 1 & $4+$ & IPHA & 0 & 0 & 0 & 0 & 0 & 0 & 0 & 0 & 0 & 0 \\
\hline LTA & 1 & 1 & 3 & 1 & 1 & 1 & LTA & 1 & 1 & 1 & 1 & 1 & 1 & 1 & 1 & 1 & 1 \\
\hline UEA-1 & 0 & 0 & 1 & 0 & 0 & 0 & UEA-1 & 0 & 0 & $2++$ & 0 & 0 & $2+$ & 0 & 0 & 0 & 0 \\
\hline ALA & 4 & 4 & 3 & 3 & $1-2$ & $4++$ & ALA & 4 & 2 & $4++$ & 4 & 2 & $4++$ & 4 & 3 & 4 & 3 \\
\hline MPA & 4 & $1-2$ & 2 & $1-3$ & 1 & $3-4++$ & MPA & $3-4$ & 2 & $2-3++$ & 4 & $2-3$ & $2-3++$ & 4 & 2 & $2-3$ & $1-2$ \\
\hline BSA-1B4 & 2 & 1 & 0 & 3 & 1 & $4+$ & BSA-1B4 & 0 & 0 & $2++$ & 0 & 0 & $2+$ & 0 & 0 & 0 & 0 \\
\hline $\mathrm{AHA}$ & 0 & 0 & $1-2$ & 0 & 0 & 0 & $\mathrm{AHA}$ & 0 & 0 & $2++$ & 0 & 0 & $2+$ & 0 & 0 & 0 & 0 \\
\hline $\mathrm{AHA}+\mathrm{N}$ & 4 & $1-2$ & 2 & $3-4$ & $1-2$ & $4+$ & $\mathrm{AHA}+\mathrm{N}$ & 4 & 2 & $2-4++$ & 4 & $2-4$ & $3-4$ & 4 & 3 & $3-4$ & 3 \\
\hline ECA & 3 & 1 & $1-2$ & 0 & 0 & $4+$ & ECA & 4 & 0 & $2++$ & 3 & 0 & $2+$ & $1-3$ & 0 & 1 & 0 \\
\hline $\mathrm{ECA}+\mathrm{N}$ & 4 & $1-2$ & 2 & 4 & $1-2$ & $2-4+++$ & $\mathrm{ECA}+\mathrm{N}$ & 4 & 1 & $2-4++$ & 4 & 1 & $2-3++$ & 4 & 3 & 3 & 2 \\
\hline DBA & 0 & 0 & 1 & 0 & 0 & 0 & DBA & 0 & 0 & $2++$ & 0 & 0 & $2+$ & 0 & 0 & 0 & 0 \\
\hline VVA & $1-2$ & 1 & 0 & 0 & 0 & 0 & VVA & 0 & 0 & $2^{++}$ & 4 & 0 & $2+$ & 0 & 0 & 0 & 0 \\
\hline HPA & $1-3$ & 1 & $1-2$ & 1 & $1-2$ & $3++$ & HPA & 1 & 1 & $2+$ & 4 & $1-2$ & $2+$ & 1 & 1 & 0 & 0 \\
\hline WFA & 4 & $1-2$ & $1-2$ & $3-4$ & $0-1$ & $4++$ & WFA & 0 & 0 & $2++$ & 0 & 0 & $2+$ & Occ 3 & 0 & 0 & 0 \\
\hline SBA & $1-2$ & 0 & $1-2$ & $1-3$ & $0-1$ & $4+$ & SBA & 0 & 0 & $2++$ & 0 & 0 & $2+$ & 0 & 0 & 0 & 0 \\
\hline $\mathrm{SBA}+\mathrm{N}$ & 2 & 1 & $1-2$ & $1-3$ & 1 & $4+$ & $\mathrm{SBA}+\mathrm{N}$ & $1-3$ & 1 & $2++$ & 4 & 1 & Occ 3 & 4 & 1 & 0 & 0 \\
\hline BSA-II & 0 & 0 & $0-1$ & 0 & $1-2$ & $4+++$ & BSA-II & $1-3$ & $1-3$ & $1-3+++$ & 4 & 1 & $1-3+++$ & $1-3$ & 1 & $1-3$ & $1-3$ \\
\hline DSA & 4 & 4 & 2 & 4 & $1-2$ & $4++$ & DSA & 4 & 1 & $4+$ & 4 & 1 & $4+$ & 4 & 2 & 3 & 2 \\
\hline STA & 4 & 3 & 3 & 4 & $2-3$ & $3-4+++$ & STA & 3 & 1 & Occ 4 & 3 & 1 & Occ 4* & 4 & 2 & $? 3$ & 1 \\
\hline LEA & 3 & $1-2$ & $1-2$ & 4 & 2 & $3+$ & LEA & 0 & 0 & $2++$ & 0 & 0 & $2+$ & 4 & 1 & 0 & 0 \\
\hline PAA & $1-2$ & 1 & 1 & $3-4$ & $1-3$ & $3-4+$ & PAA & 0 & 0 & $2++$ & 0 & 0 & $2+$ & $3-4$ & 0 & 0 & 0 \\
\hline $\mathrm{PAA}+\mathrm{N}$ & $2-3$ & 1 & $1-2$ & $3-4$ & $1-3$ & $3-4+$ & $\mathrm{PAA}+\mathrm{N}$ & 1 & 0 & $2++$ & $1-2$ & 1 & 1 & 4 & 1 & 0 & 0 \\
\hline WGA & $3-4$ & 1 & 2 & $3-4$ & $1-3$ & $4++$ & WGA & 4 & $1-2$ & $4+$ & 4 & $1-2$ & $3-4++$ & 4 & $1-2$ & $2-3$ & 1 \\
\hline$W G A+N$ & $3-4$ & 1 & 2 & $3-4$ & $1-3$ & $4++$ & $W G A+N$ & $3-4$ & $1-2$ & $4+$ & 4 & $1-2$ & $4+$ & 4 & $1-2$ & 2 & 1 \\
\hline SNA-1 & 4 & 3 & 3 & 4 & 3 & $3-4+++$ & SNA-1 & 4 & 3 & $4+$ & 4 & 3 & $4+$ & 4 & 3 & $2-3$ & $2-3$ \\
\hline SNA-1+N & 4 & 3 & 3 & 4 & 3 & $3-4+++$ & SNA-1+N & 4 & 3 & $4+$ & 4 & 3 & 3 & 4 & 3 & $2-3$ & $2-3$ \\
\hline MAA & 4 & $1-2$ & 2 & 4 & $1-2$ & $4+$ & MAA & 3 & 1 & $4+$ & 4 & $1-2$ & $4+$ & 4 & 3 & 3 & 3 \\
\hline $\mathrm{MAA}+\mathrm{N}$ & 1 & 0 & 1 & 0 & 0 & 0 & $\mathrm{MAA}+\mathrm{N}$ & 0 & 0 & $2+$ & $0-2$ & 0 & $2+$ & 4 & 1 & 0 & 0 \\
\hline
\end{tabular}

\section{$\underline{\text { Yolk Sac }}$}


Ascending maternal

blood channel
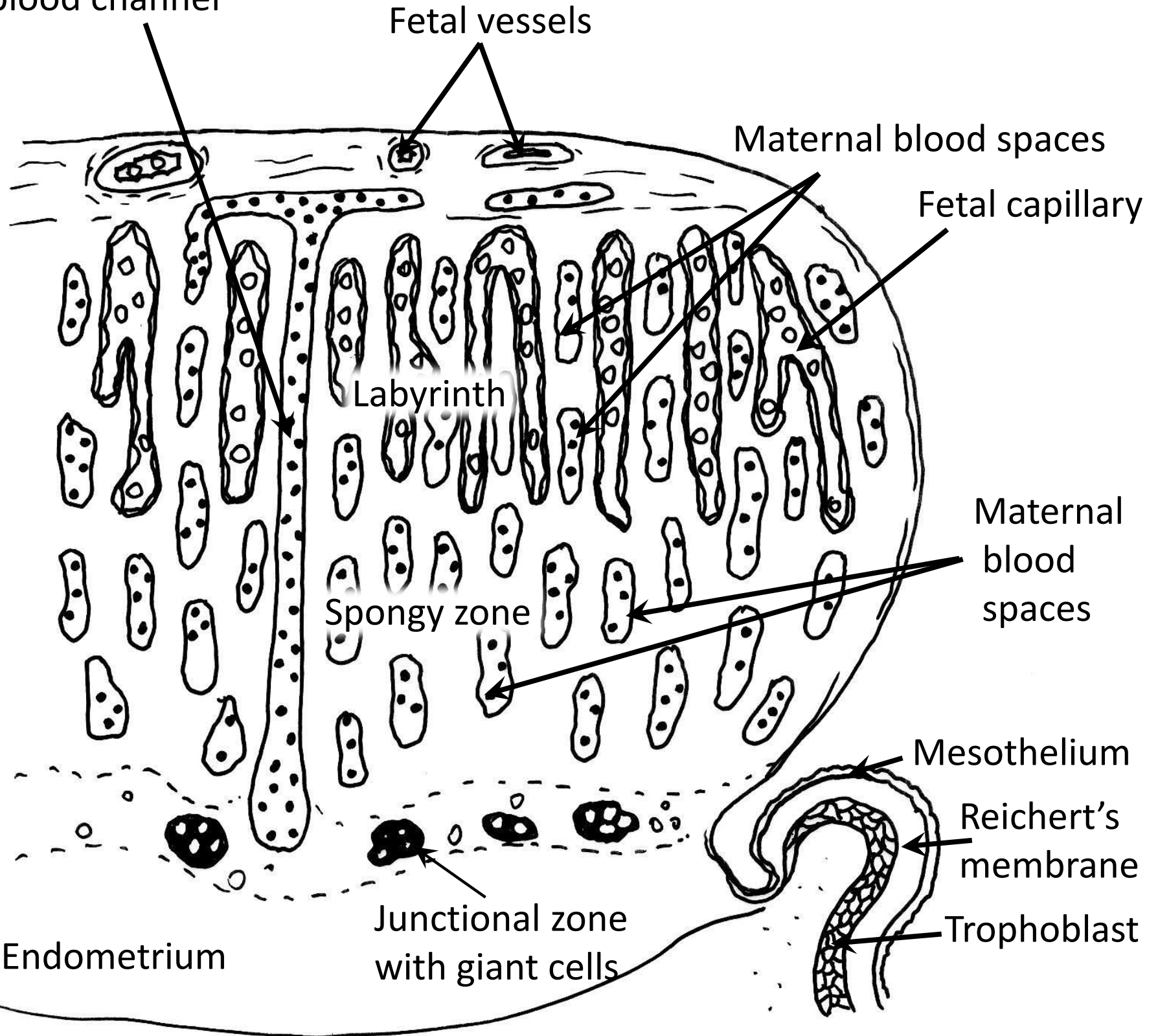

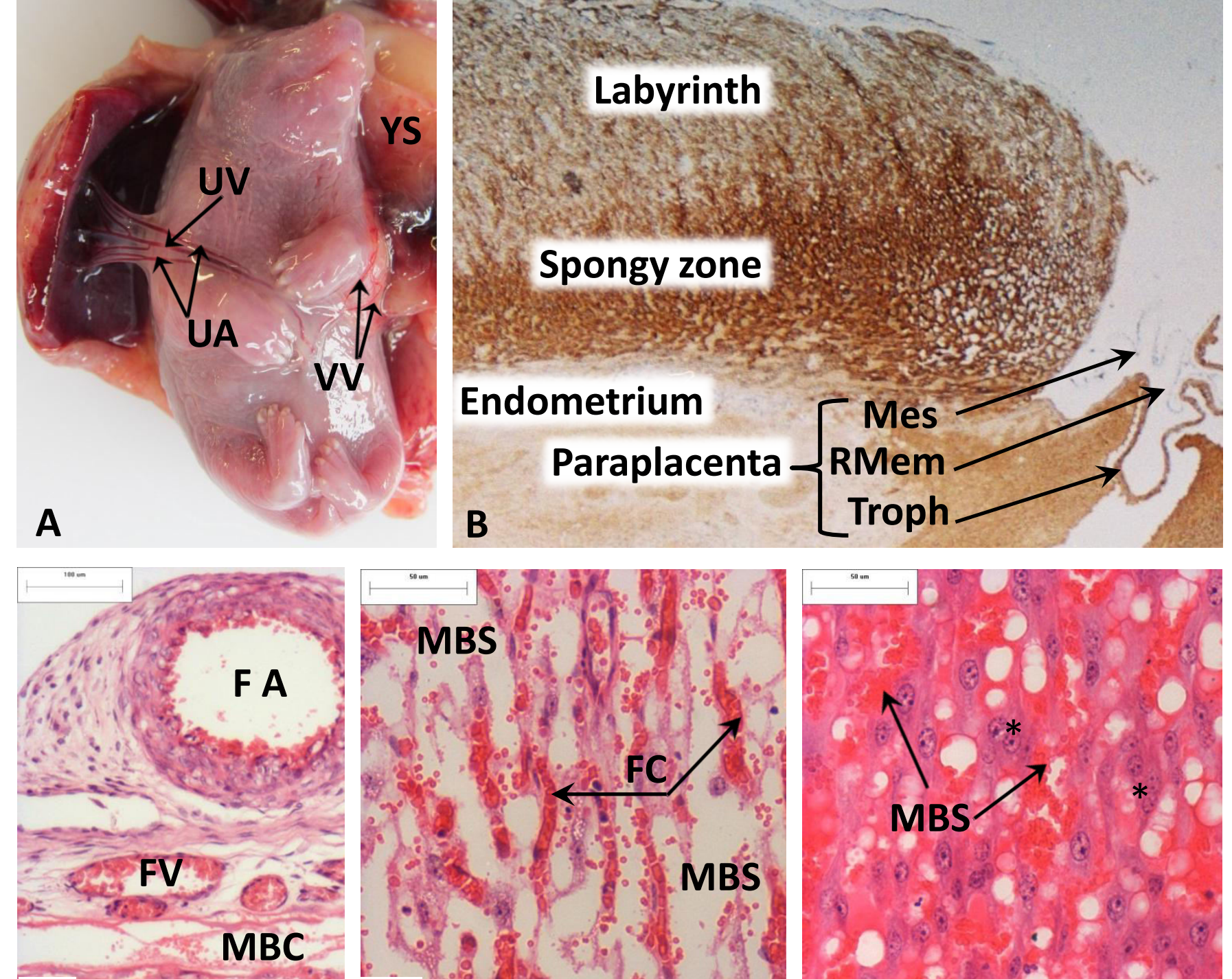

$C$ Wustent
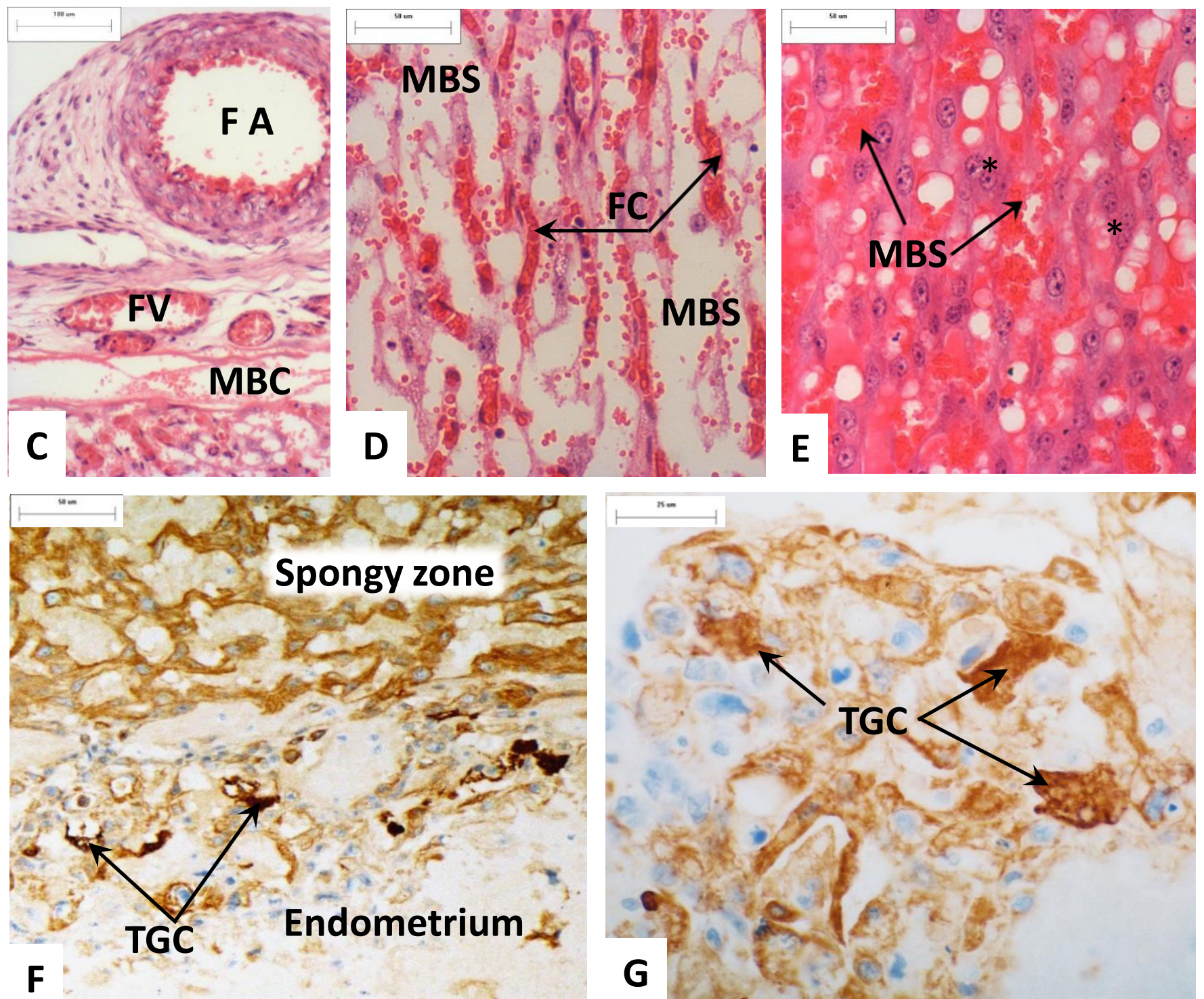

Spongy zone
Spons
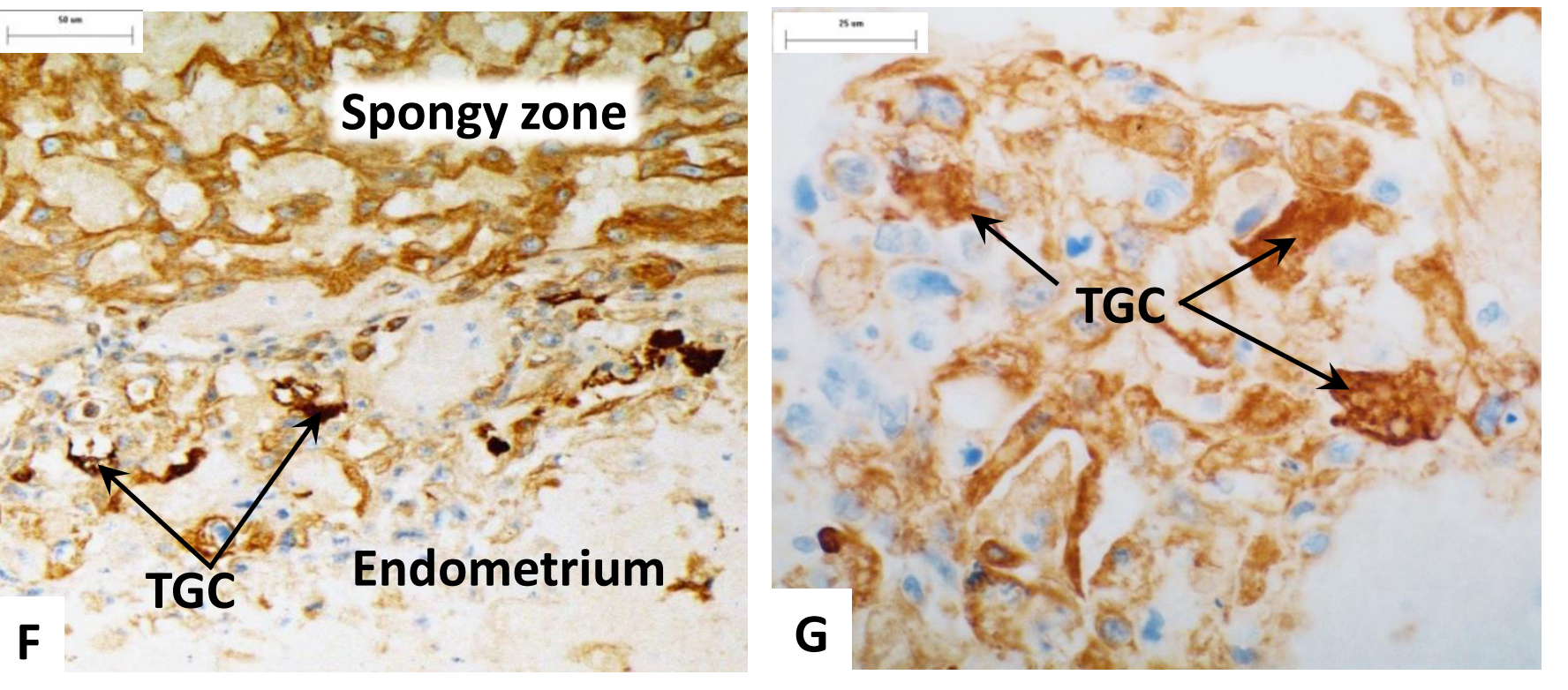

$\mathbf{F}$

Endometrium $\not$

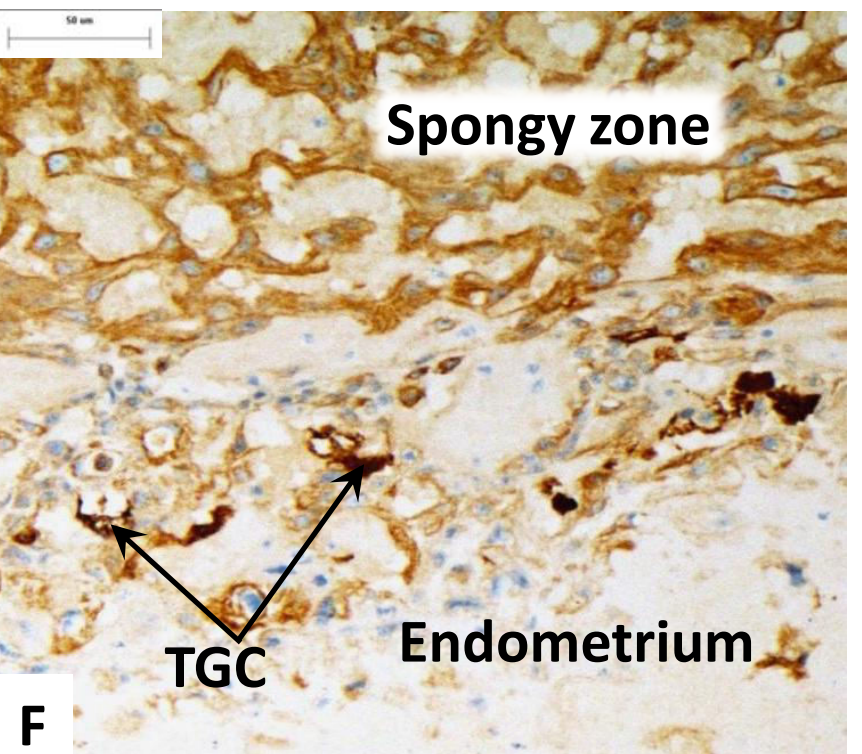
Troph 
Figure

Click here to download Figure: Hedgehog Figure 3.pptx
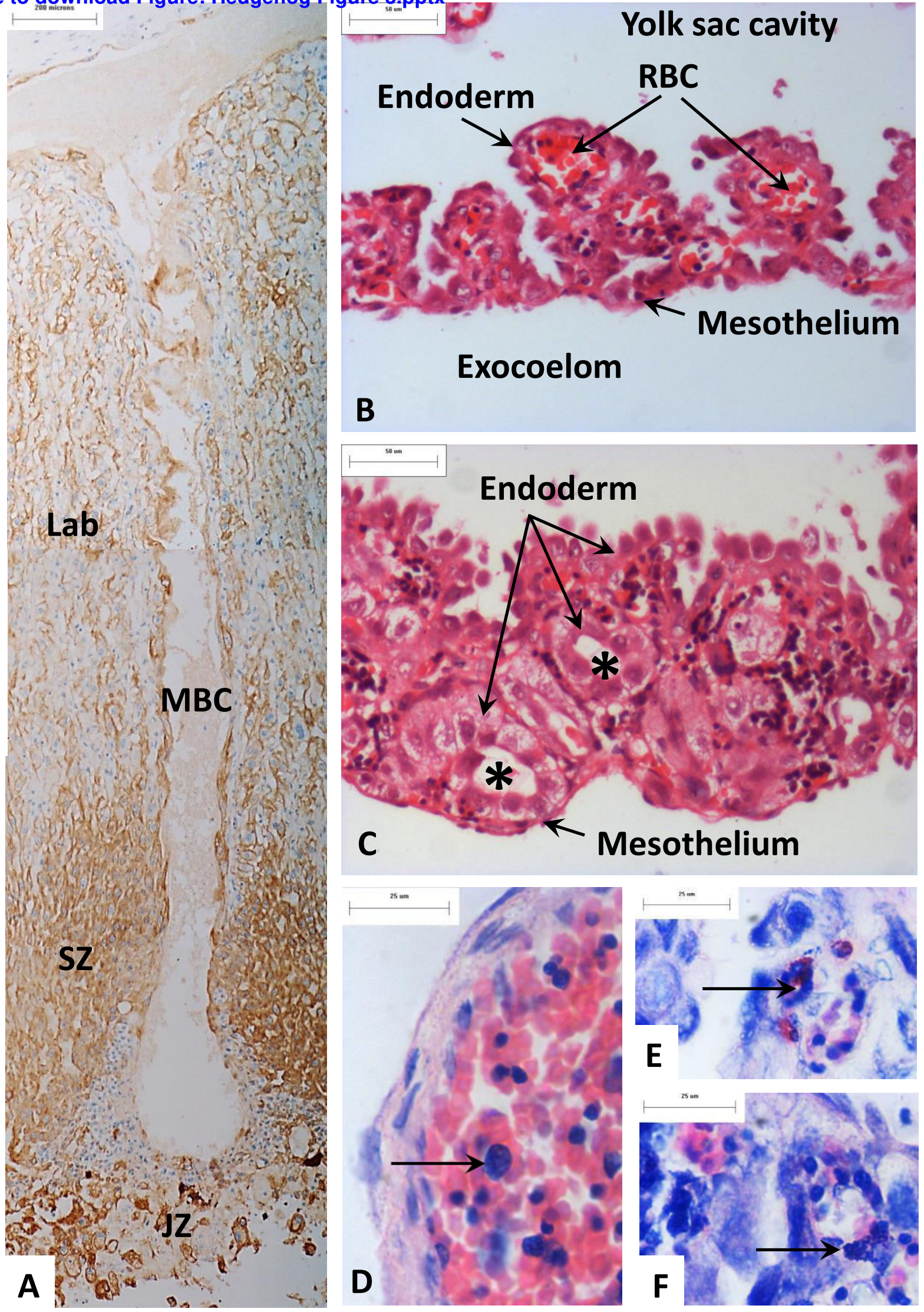
Figure

Click here to download Figure: Hedgehog Figure 4.pptx
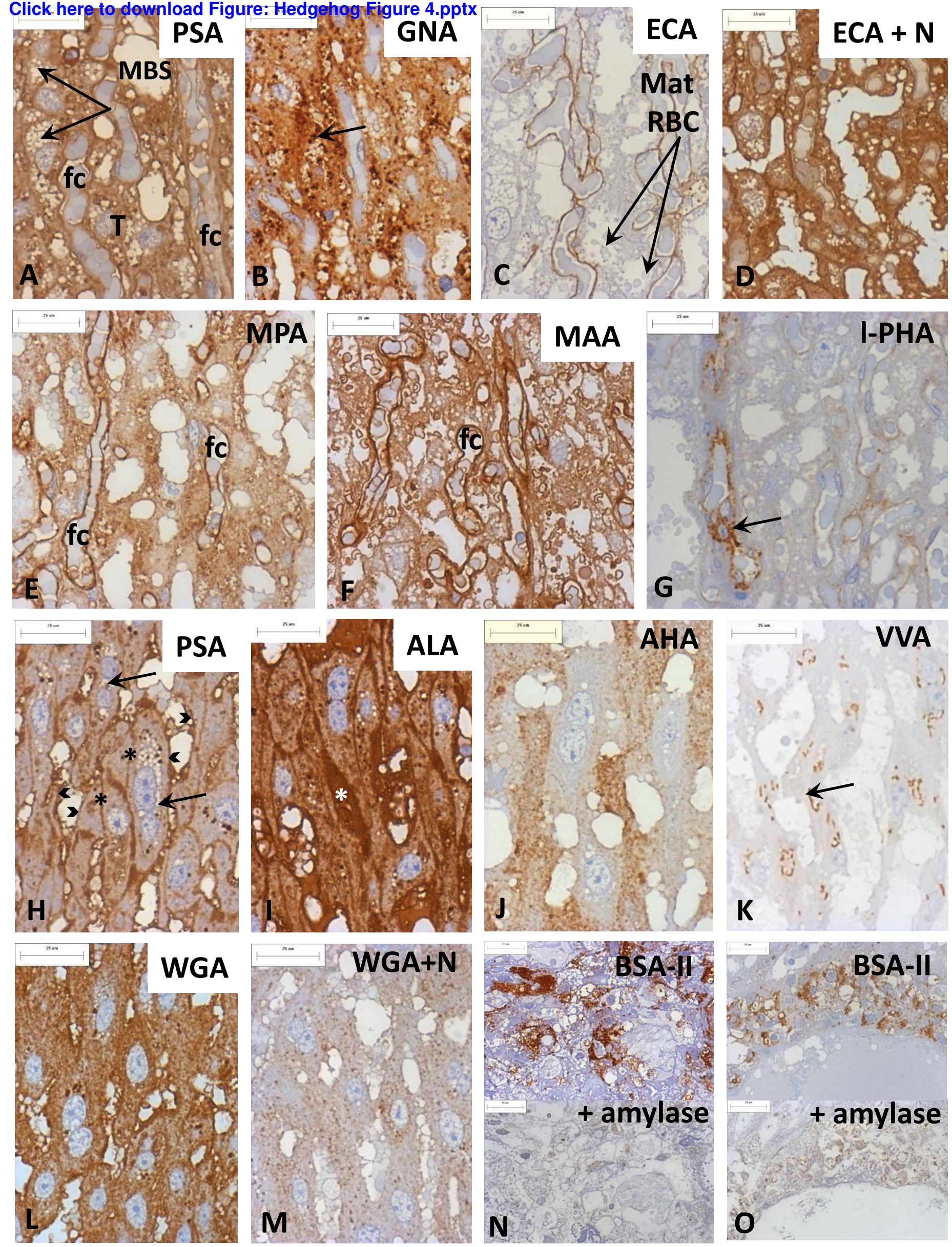

VVA

K 
Figure

Click here to download Figure: Hedgehog Figure 5 Coktx Mes
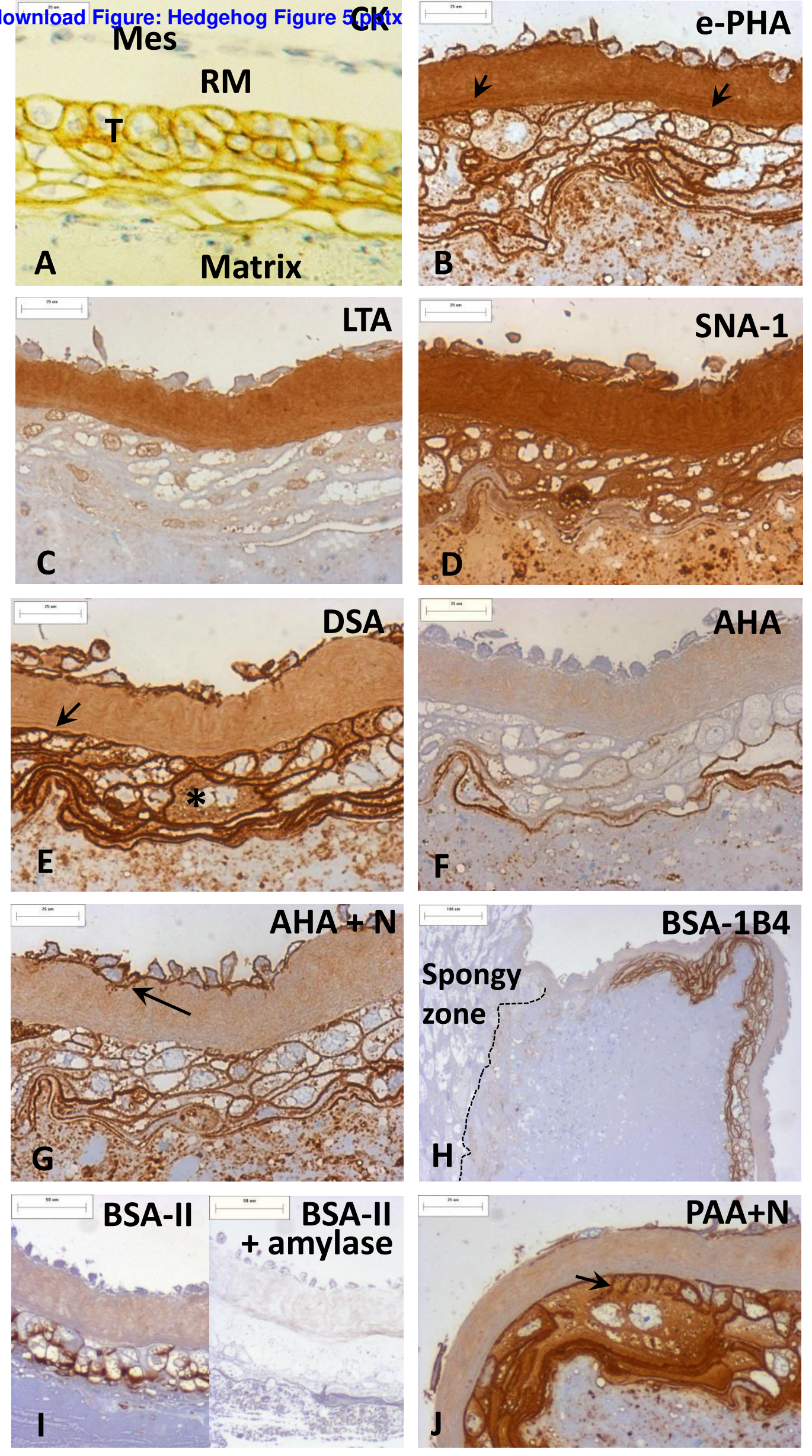


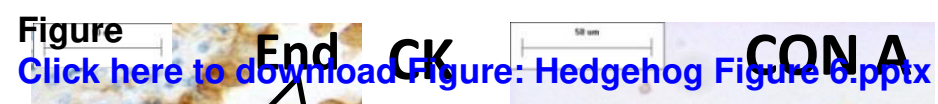

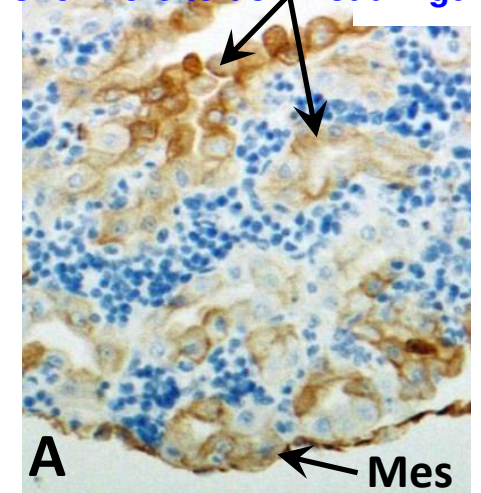
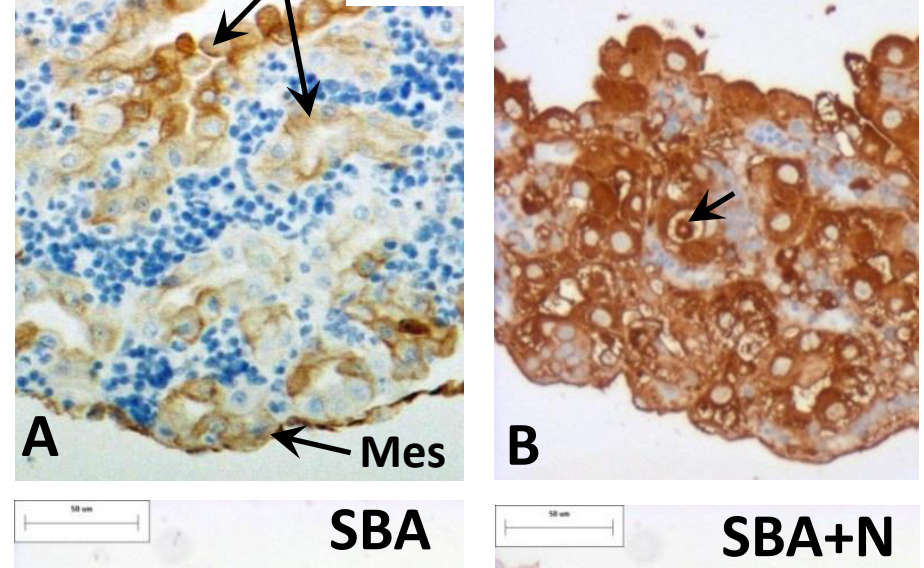

E
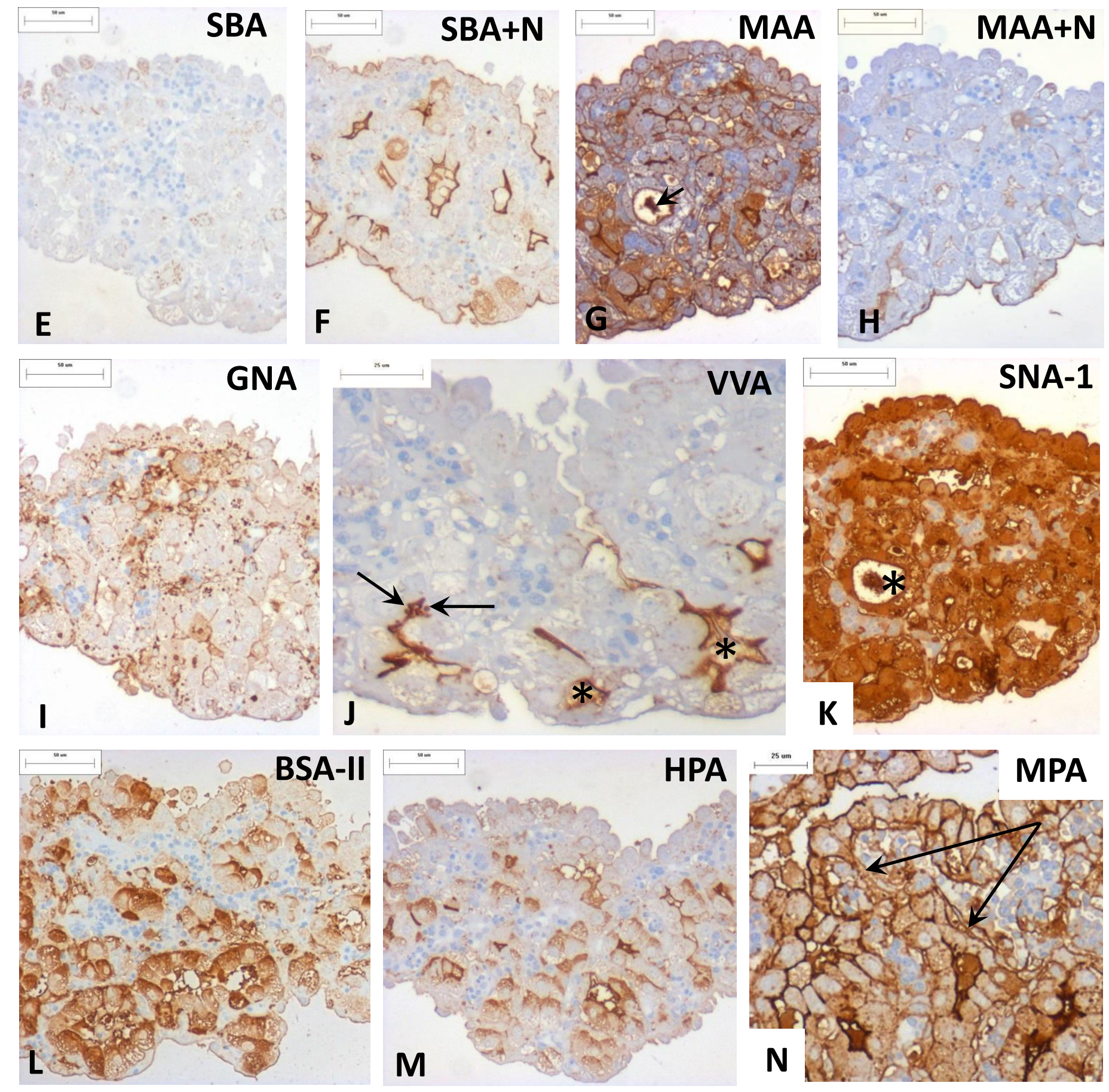

SNA-1

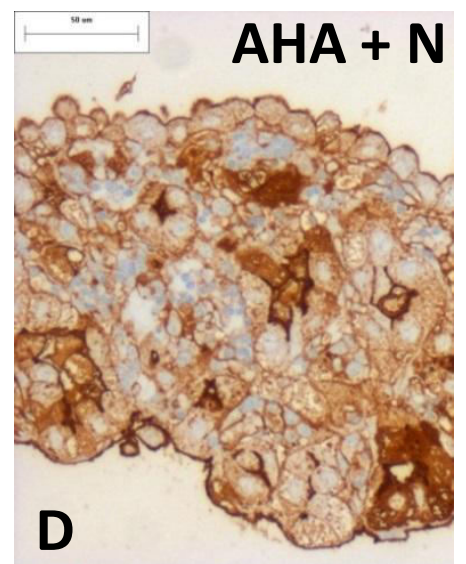

GNA 